\title{
The Impact of Health Expenditure on Economic Growth in Algeria
}

\author{
Merizek Admane ${ }^{1} \&$ Samiha Slimani ${ }^{2}$ \\ ${ }^{1}$ The High Business School of Algeria, Algiers, Algeria \\ ${ }^{2}$ M'hamed Bougara University, Boumerdes, Algeria \\ Correspondence: Samiha Slimani, M'hamed Bouhara University, Boumerdes, Algeria. Tel: 213-666-902-802. \\ E-mail: samiha.slimani@gmail.com
}

Received: September 24, 2019

Accepted: November 16, 2020

Online Published: January 5, 2021

doi:10.5539/ijef.v13n2p25

URL: https://doi.org/10.5539/ijef.v13n2p25

\begin{abstract}
The present study aims to investigate the impact of health expenditure on economic growth in Algeria for the period 1960-2016. Using data from the World Bank database, the Autoregressive Vector model and Granger causality, findings show that health expenditure positively affects economic growth in the short term; which means that the study's hypothesis is proved. The results therefore reveal the increasing importance of investment in the health sector in order to improve economic growth indicator in Algeria.
\end{abstract}

Keywords: health expenditure, economic growth, Auto Regressive Model and Granger Causality

\section{Introduction}

The majority of countries seek to increase the gross domestic product (GDP) by increasing the contribution of the four sectors affecting it: consumption, investment, public spending and foreign trade.

Many studies about the relationship between government expenditure in general and economic growth have been conducted and reached different results. Some of them have confirmed the one-way causal relationship, where GDP growth leads to the growth of government spending. Conversely, other studies have confirmed a two-ways causal relationship.

However, many studies have examined the relationship between health expenditure and economic growth, as increased health spending will improve health status and thus reduce morbidity, lower mortality and increase life expectancy. These studies have been conducted in different contexts, and the question which is worth answering is: what is the nature of the relationship between health expenditure and economic growth in Algeria?

A preliminary assumption to answer this question is that there is a positive relationship between health expenditure and economic growth in Algeria.

The study aims to uncover the relationship between health expenditure and economic growth in order to achieve results that may help policy makers and decision-makers in the future.

\section{Review of Literature}

Here is a summary of several studies that have dealt with the relationship between health expenditure and economic growth:

Atilgan, Kilic, and Ertugrul (2016) aimed to study the hypothesis of health-based growth for the Turkish economy. Data of the period 1975-2013 were used to test the co-integration relationship between economic growth and health expenditure. The Autoregressive Distributed Lag (ARDL) model was used to examine the long-term relationship between health expenditure and economic growth. Results show that the increase of 1 percent in health expenditure per inhabitant leads to 0.434 percent increase in the gross domestic product (GDP) per inhabitant. These results are in line with those of the model of "Kalman Filter". The study showed that the hypothesis of health-based growth is proven for Turkey.

Yazdi and Khanalizadeh (2017) examined the role of environmental quality and economic growth in determining health expenditure of the Middle Eastern and North African (MENA) countries during the period 1995-2014. Using the Autoregressive Distributed Lag (ARDL) model to determine the impacts of economic growth and the quality of environment on health expenditure. Long-term results show that income, $\mathrm{CO}_{2}$ emissions and PM10 have significant positive effects on health expenditure. The results also show that income elasticity is inflexible; 
moreover, health expenditure is insensitive to income and adaptability to income changes in the Middle East and North Africa.

Piabuo and Tieguhong (2017) compared the impact of health expenditure on economic growth in the Central African Economic countries and Monetary Community and five other countries that succeeded in raising health expenditure by $15 \%$ as stipulated in the "Abuja" declaration in 2001. The results show that health expenditure positively affects the economic growth for both samples. Where a one unit increase in health expenditure leads to a 0.38 and 0.3 unit increase in gross domestic product per inhabitant and for the CEMAC and the five other African countries that have achieved the stated goal of the declaration respectively; a significant difference of 0.08 unit between the two samples. Using the ordinary least squares (OLS), the fully modified ordinary least squares (FMOLS) and the dynamic ordinary least squares (DOLS) methods for analysis, the study's results recommended the necessity of adhering to the Abuja Declaration.

Gangal and Gupta (2013) aimed at presenting the impact of health expenditure on economic growth in India during the period 1998-2012. The study included annual data for total public expenditure and gross domestic product per inhabitant as an indicator of economic growth. The use of "granger" causality, "co-integration" test and "single-root" test (ADF) showed that there is a positive impact of total public expenditure on economic growth.

Subhalaxmi and Padmaja (2011) aimed to determine the conditions in which changes in the components of public expenditure for health can lead to economic growth. The study aimed to establish a relationship between the different components of public expenditure for health and economic growth in India covering the period 1990-1991 to 2007-2008. To achieve this objective, an econometric analysis was carried out using the co-integration panel and the Grange causality relationship using two types of time series: time series data across India, and panel data on 16 key Indian states. The results indicate that there is a causal effect of GDP on health expenditures in both short and long terms. However, health expenditures have no effect on GDP in short or long term. In addition, results revealed that there is no link between gross domestic product and capital expenditure on health. However, results of the states' data analysis indicate that GDP affects short- and long-term health expenditures, while health expenditures affect only the long-term GDP. Regarding the results achieved at the level of India as a whole, it was found that capital expenditure on health had no meaningful relationship with growth in the context of states.

Bakare and Sanmi (2011) examined the relationship between health expenditure and economic growth in Nigeria using the multiple regression analysis. Data analysis showed a significant positive relationship between the two variables. The study therefore recommended the policy-makers in Nigeria to pay greater attention to the health sector by increasing the annual budget allocations for this sector. However, the key to achieve good results is not usually by increasing budgetary allocations but by implementing a general financial system that, as far as possible, links specific decisions on expenditure to income and ensures that the allocated funds are used as transparently as possible.

Akram and HaqPadda (2008) tackled the impact of various health indicators on economic growth. Co-integration, error correction, and Granger Causality were used on time series for the period 1972-2006 in Pakistan. It was found that the GDP per inhabitant is positively affected by long-term health indicators, while this effect is not statistically significant in the short term. Consequently, health indicators have significant impact on long-term economic growth.

Ali, Khalaf, and Al-Hiti (2009) aimed to estimate and analyze the effect of health expenditure and education expenditure on economic growth in both Jordanian and the Saudi Arabian economy. The optimal value of both educational and health expenditures for economic growth was estimated by testing the quadratic relationships of educational and health expenditure as a proportion of GDP. Results showed that education in both Jordan and Saudi Arabia had a significant positive impact on economic growth. While expenditure on health had a positive insignificant effect.

Maitra and Mukhopadhyay (2012) have examined the role of public expenditure on health and education sectors in enhancing the gross domestic product of 12 countries in Asia and the Pacific over the past three decades. In six of these countries, namely Bangladesh, Kiribati, Malaysia, the Maldives, the Philippines and the Republic of Korea, Johansen co-integration tests confirmed the existence of co-integration relations. While in the remaining countries, namely Fiji, Nepal, Singapore, Sri Lanka, Tonga and Vanuatu, co-integrating relations were absent. Education spending was found to have raised GDP in Bangladesh, Fiji, Kiribati, Maldives, Nepal, Singapore, Sri Lanka, Tonga and Vanuatu. On the other hand, health-care spending contributed to GDP growth in Bangladesh, Nepal, the Philippines, Singapore and Sri Lanka. In the Philippines, spending on education had a negative impact 
on GDP, while in Kiribati, Maldives and Vanuatu, the impact of health-care spending on GDP was found to be negative. In the case of Malaysia and Korea, neither education spending nor health-care expenditure exhibited a significant impact on GDP.

By examining the previous studies, it is concluded that:

The studies have agreed that there is a causal relationship between health expenditure and economic growth.

The studies have agreed on the impact term, emphasizing long-term impact, except for one study that has detected short-term impact in some states only.

The tests used in the detection of the causal relationship differed according to environment and to the study's objective.

The lack of Arabic studies in general and Algerian in particular, which dealt with the causal relationship between health expenditure in particular and economic growth, but mostly directed to uncover the causal relationship between government expenditure and economic growth.

Unlike most studies that have focused on the impact of other variables on economic growth, as well as the novelty of the period, the importance of this study is reflected in its focus on the nature of the relationship between health expenditure and economic growth in Algeria

\section{The Relationship Between Health Expenditure and Economic Growth}

The economic history of the last 150 years shows that economic growth has coincided with rising public expenditure since the mid-nineteenth century. This long-term association was known as the Wagner Act. Wiseman and Peacock studied the evolution of public spending in the United Kingdom during the period 1890-1955, saying that public spending in the UK was subject to public law. Their main hypothesis was that government spending grew as a result of revenue growth. This hypothesis, however, has focused on political and non-economic factors such as unrest, wars and social tremors which result in an irregular increase in public spending and leaps (Kaddouri, 2016).

Economic studies indicate direct links between economic performance and health indicators such as life expectancy. In addition, there are other variables such as geography and demography that indirectly link health with economic performance. Geography, especially the orbital location, is closely related to diseases, which in turn affect economic performance (Gounash, 2004).

The relationship between health state and growth rate during the period 1950-1980 was analyzed starting by the transition from growth to health improvement. In other words, the increase in average income in the economy enables individuals and society to better deal with health problems. But the recent trend in research has attempted to demonstrate the positive impact of health on growth, i.e., the transition from health to economic growth (Kocoglu \& David, 2009).

Three questions dominate the debate on the relationship between economic activity and health expenditure: (Cornillou, 2012).

The first, which is related to the weight of health expenditure in demand, is linked to the direct leadership role that health sector can play: Can economic growth be driven by demand for health care services?

The second question concerns the role of health in productivity efficiency. Since healthy people are more able to perform well. Spending on health care can stimulate overall supply competitiveness: can health be considered a productive investment?

The last question concerns the role of health expenditure in organizing economic activity: through its stability, is health spending an effective means of control in a crisis situation?

Richard (2004), in an attempt to clarify the relationship between health expenditure and economic growth, argued that previously, the development of the country was seen as the first priority. And then health spending is carried out if it was not necessary for the development. But the new direction of thinking is if you want a successful economic development of the country, you need first to spend a good amount of money on health and health care in the development process. Which is the mechanism that leads health and health care to the economic growth through the development of human capital, referring to education, training and health (Ali, Khalaf, \& Al-Hiti, 2009).

If we spot light on the causal relationship between health spending and economic growth, we realize that it is not as simple as previously mentioned, and the question is asked again: Can the health sector help to raise the pace of potential growth of the economy? 
A number of economists, who focus on identifying the structural factors of growth, point out that health is one of these factors, along with education, public investment, and research. In order to increase the rate of economic growth in a sustainable manner, it is necessary to increase the rate of structural productivity growth. It is quite clear that the population's health state can have an impact on the productivity efficiency of the labor force. If the situation is bad, this will lead to further disruptions and reduced-motivation and efficiency. Thus, the population's health state can be considered as an intangible factor of production, such as education, which can raise productivity.

The use of life expectancy as an indicator for the population's health state, based on an economic estimate using a sample of developed and developing countries over the periods 1940-1980 and 1960-2000, shows that health and improved health have a positive impact on per capita GDP growth rates, including OECD countries which confirmed it only between 1940 and 1980 .

Thus, increasing health spending, provided that it leads to real increase in the population's health and life expectancy, can be very effective economically if it can increase welfare.

The question of the structural contribution of health expenditures to economic growth finally calls for a nuanced response. For the increase in spending to be favorable, it must first be ensured that it will lead to an effective improvement in the health state. This first condition simply refers to the microeconomic issue of the technical efficiency of the health care system. The second condition is that the welfare supplement obtained corresponds to the wishes of individuals. The third condition, assuming that the increase in expenditure does not increase monetary income, is that the financing is immediate; the material investments in the sector (construction of hospitals, investment in long-term equipment, etc.) can be financed by borrowing but not by current expenditure (Cornillou, 2012).

Since health and development are closely linked, lack of attention to health sector will feed a vicious circle of economic and social instability, weak development, fall of economic productivity and economic growth. The World Health Organization (WHO) revealed that 57 countries in the world suffer from a lack of basic life-saving interventions such as vaccinations, especially during childhood. In addition, the limited financial budgets allocated to health care in developing countries have led to economic and social instability, which has adversely affected development (Mukhtar, 2013).

The World Health Organization (WHO) Committee on Macroeconomics and Health recommended increasing health spending as a means of promoting economic growth and raising both health status and family income (Michael \& Maureen, 2009).

\section{Method}

\subsection{Data}

As mentioned above, the study aims to estimate the relationship between health expenditure and economic growth in Algeria. The study is based on data taken from the website of the World Bank's Statistics Division about GDP and health spending during the period 1960-2016.

\subsection{The Econometric Model}

The Vector Auto regression Model (VAR) is a multivariate model on which the current value of a variable is interpreted by past values of the same variable and other variables in the model, and it helps to measure the interrelationships between time series variables. It is used in the study to investigate the impact of health sector spending on economic growth in Algeria through the use of annual time series for the period 1960-2016.

The VAR model of $\mathrm{p}$ level for a set of $(\mathrm{m})$ variables in the study can be written as follows:

$\operatorname{VAR}(p)$ Model

Where:

$$
Y t=A_{0}+A_{1} Y_{t-1}+A_{2} Y_{t-2}+\ldots \ldots \ldots \ldots \ldots \ldots+A_{P} Y_{t-P}+u_{t}
$$

$\mathrm{A}_{0:}$ a ( $\left.\mathrm{m} \times 1\right)$ vector of constants.

$\mathrm{m}$ : The number of variables included in the study (called endogenous variables).

A1 ... AP: coefficient matrices ( $\mathrm{m} \times \mathrm{m}$ ) (for each; $\mathrm{i}=1,2, \ldots, \mathrm{p}$ ).

$\mathrm{u}_{\mathrm{t}}: \mathrm{a}(\mathrm{m} \times 1)$ vector of error terms.

Equation (1) can be simplified in the case of $\mathrm{p}=2$ with two endogenous variables to the following formula:

VAR (2) Model 


$$
\begin{gathered}
y_{1 t}=A_{10}+A_{11} y_{1 t-1}+B_{11} y_{2 t-1}+A_{12} y_{1 t-2}+B_{12} y_{2 t-2}+u_{1 t} \\
y_{2 t}=A_{20}+B_{21} y_{2 t-1}+A_{21} y_{1 t-1}+B_{22} y_{2 t-2}+A_{22} y_{1 t-2}+u_{2 t}
\end{gathered}
$$

Based on the above, the model of the study can be presented after the logarithm transformation as following: VAR (2) Model

$$
\begin{aligned}
& L N G D P G_{t}=A_{10}+A_{11} L N G D P G_{t-1}+B_{11} L_{N H E P R_{t-1}}+A_{12} L N G D P G_{t-2}+B_{12} L N H E P R_{t-2}+u_{1 t} \\
& L_{N H E P R_{t}}=A_{20}+B_{21} L_{N H E P R_{t-1}}+A_{21} L_{N G D P G_{t-1}}+B_{22} L_{N H E P R_{t-2}}+A_{22} L N G D P G_{t-2}+u_{2 t}
\end{aligned}
$$

Where:

LNGDPG $_{\mathrm{t}}$ : Logarithm of GDP growth rate during the year $\mathrm{t}$.

$\mathrm{LNGDPG}_{\mathrm{t}-1}$ : logarithm of GDP growth rate during the year $\mathrm{t}-1$.

$\mathrm{LNGDPG}_{\mathrm{t}-2}$ : logarithm GDP growth rate during the year $\mathrm{t}-2$.

LNHEPR $_{\mathrm{t}}$ : Logarithm of government expenditure on health ratio during the year $\mathrm{t}$.

LNHEPR $_{\mathrm{t}-1}$ : Logarithm of government expenditure on health ratio during the year $\mathrm{t}-1$.

$\mathrm{LNHEPR}_{\mathrm{t}-2}$ : Logarithm of government expenditure on health ratio during the year $\mathrm{t}-2$.

$\mu_{\mathrm{t}}$ : Random error term during the year $\mathrm{t}$.

\section{Results}

The building of the VAR study model is based on the following steps:

1) Test of stationarity in time series

2) Determination of the number of lagged periods.

3) Test of Granger causality

4) Estimation of the study's model.

5) Evaluation of the study's model.

6) Estimation of the impulse functions' response.

7) Analysis of variance for the study's model.

\subsection{Stationarity Test of Time Series for the Model's Variables}

Table 1. ADF test results for unit roots

\begin{tabular}{ccccc}
\hline Variables & Models & Level & First diff & Decision \\
\hline LNGDPG & Intercept & 0.0019 & 0.0000 & $\mathrm{I}(0)$ \\
& Trend and Intercept & 0.0023 & 0.0000 & $\mathrm{I}(0)$ \\
& None & 0.0611 & 0.0000 & $\mathrm{I}(1)$ \\
\hline \multirow{2}{*}{ LNHEPR } & Intercept & 0.0664 & 0.0099 & $\mathrm{I}(1)$ \\
& Trend and Intercept & 0.0934 & 0.0442 & $\mathrm{I}(1)$ \\
\hline
\end{tabular}

Table 1 reports the Augmented Dickey \& Fuller unit root test for the two variables. Results show that the LNGDPG variable is stationary at level $\mathrm{I}(0)$ and does not contain a unit root. Otherwise, the LNHEPR variable contains a unitary root and is stationary at the first difference $\mathrm{I}(1)$.

Since the estimation of the VAR model requires stationary time series, we make the first difference on the LNHEPR variable in order to eliminate the unit root and make the variable series stationary at the I (0) level, as shown in Table 2.

Table 2. ADF test results for LNHEPR after the first difference

\begin{tabular}{cccc}
\hline Variables & Models & Level & Decision \\
\hline \multirow{2}{*}{ LLNHEPR } & First Model: Intercept & 0.0099 & $\mathrm{I}(0)$ \\
& Second Model: Trend and Intercept & 0.0442 & $\mathrm{I}(0)$ \\
& Third Model: None & 0.0005 & $\mathrm{I}(0)$ \\
\hline
\end{tabular}


Based on results in Table 2, the study's model (after disposing of the unit root of LNHEPR) is presented in to the following formula:

VAR (2) Model

$$
\begin{aligned}
& L N G D P G_{t}=A_{10}+A_{11} L N G D P G_{t-1}+B_{11} \Delta L N H E P R_{t-1}+A_{12} L N G D P G_{t-2}+B_{12} \Delta L N H E P R_{t-2}+u_{1 t} \\
& \Delta L N H E P R_{t}=A_{20}+B_{21} \Delta L N H E P R_{t-1}+A_{21} L N G D P G_{t-1}+B_{22} \Delta L N H E P R_{t-2}+A_{22} L N G D P G_{t-2}+u_{2 t}
\end{aligned}
$$

Where:

$\triangle$ LNHEPR $_{\mathrm{t}}$ : The first difference in the logarithm of the government expenditure on health ratio during the year $\mathrm{t}$.

$\triangle \mathrm{LNHEPR}_{\mathrm{t}-1}$ : The first difference in the logarithm of the government expenditure on health ratio during the year $\mathrm{t}-1$.

$\triangle \mathrm{LNHEPR}_{\mathrm{t}-2}$ : The first difference in the logarithm of the government expenditure on health ratio during the year $\mathrm{t}-2$.

\subsection{Determination of the Number of Lags}

Before estimating the VAR model, it is important to determine the number of lags in order to avoid the problem of autocorrelation of errors, which can negatively affect the quality of the estimated model. Table (3) shows the number of lags according to several criteria.

Table 3. Determination of the number of lags according to several criteria

\begin{tabular}{ccccccc}
\hline Lag & LogL & LR & FPE & AIC & SC & HQ \\
\hline 0 & 51.686 & & $6.88 \mathrm{e}-06^{*}$ & -6.210 & -6.114 & -6.205 \\
1 & 52.879 & 1.939 & $9.86 \mathrm{e}-06$ & -5.859 & -5.570 & -5.845 \\
2 & 59.981 & 9.765 & $6.93 \mathrm{e}-06$ & -6.247 & -5.764 & -6.223 \\
3 & 63.155 & 3.569 & $8.35 \mathrm{e}-06$ & -6.144 & -5.468 & -6.109 \\
\hline
\end{tabular}

The three criteria LR, AIC \& HQ indicate the need to take two lags when estimating the VAR model.

\subsection{Granger Causality Test}

Results of the Granger causality test are presented in the following table:

Table 4. Granger Causality Test

\begin{tabular}{lllc}
\hline Dependent Variable: $\mathbf{A L N H E P R}$ & & & \\
\hline Exluded & Chi-sq & Df & Prob. \\
\hline LNGDPG & 1.128978 & 2 & 0.5687 \\
ALL & 1.128978 & 2 & 0.5687 \\
\hline Dependent Variable: LNGDPG & & & \\
\hline Exluded & Chi-sq & df & Prob. \\
\hline$\Delta$ LNHEPR & 13.72769 & 2 & 0.001 \\
ALL & 13.72769 & 2 & 0.001 \\
\hline
\end{tabular}

Results in Table 4 show that LNGDPG does not Granger-cause LNHEPR at 5\% significance level. While the LNHEPR variable Granger-causes the LNGDPG variable at a 5\% significance level. Therefore, government spending on health explains GDP while the reverse is incorrect.

\subsection{VAR Model Estimation}

The model is estimated based on the results of determining the number of lags (two lags) and those of the causality test. Results of the model estimation are summarized in Table 5.

\begin{tabular}{|c|c|c|c|c|c|}
\hline \multicolumn{6}{|c|}{ LNGDPG $=0.35-3.98 \Delta$ LNHEPR $(-1)+8.38 \Delta$ LNHEPR(-2)+ 0.24 LNGDPG(-1) + 0.11 LNGDPG(-2) } \\
\hline & Constant & $\triangle \mathrm{LNHEPR}(-1)$ & $\triangle \mathrm{LNHEPR}(-2)$ & LNGDPG(-1) & LNGDPG(-2) \\
\hline t-statistic & 2.8 & -1.7 & 3.52 & 1.434 & 0.68 \\
\hline R-squared & 0.573 & & Adj.R-squared & 0.431 & \\
\hline F-statistic & 4.031 & & & & \\
\hline
\end{tabular}

Table 5. Results of the VAR model estimation 


\section{A) Statistical interpretation of the study's model}

Table 5 shows that the government spending on health ratio lagged 2 periods can be accepted because the calculated T-student value (3.52) is greater than the tabulated value (1.95) at 5\% level of significance. While the rest of the parameters are insignificant at 5\% level of significance. For the general quality of the model, Fisher's statistic is (4.31) is greater than the tabulated value (2.53), which means that the model is significant at $5 \%$ level of significance. So the model can be accepted in general. The R-square adjusted is 0.431 which indicates that the explanatory variables explain $43.10 \%$ of changes in the GDP growth rate.

\section{B) Economic explanation of the study model}

The results in Table 5 show that government expenditure on health lagged by two periods has a positive impact on the GDP growth rate.

\subsection{Evaluation of the Study's Model}

The study's model will be evaluated by testing the normal distribution of residuals and testing the absence of autocorrelation of errors and by testing the VAR stability.

\section{A) Jarque-Bera test of normality of residuals}

Table 6. Jarque-Bera normality test of residuls

\begin{tabular}{cccc}
\hline Component & Jarque-Bera & df & Prob. \\
\hline 1 & 0.0519 & 2 & 0.9744 \\
2 & 1.9942 & 2 & 0.3689 \\
Joint & 2.0462 & 4 & 0.7273 \\
\hline
\end{tabular}

Results of the Jarque-Bera test shown in Table 6 indicate that the null hypothesis of the first and second equations of the study's model is acceptable.

\section{B) LM Test of the absence of autocorrelation of errors}

Table7. LM Test of the absence of autocorrelation of errors

\begin{tabular}{ccc}
\hline Lags & LM-stat & Prob \\
\hline 1 & 4.502 & 0.3423 \\
2 & 1.777 & 0.7766 \\
3 & 1.840 & 0.7652 \\
4 & 5.834 & 0.2118 \\
5 & 1.186 & 0.8802 \\
6 & 4.257 & 0.3722 \\
7 & 3.569 & 0.4674 \\
8 & 2.916 & 0.5719 \\
9 & 1.350 & 0.8527 \\
10 & 5.529 & 0.2372 \\
11 & 3.489 & 0.4795 \\
12 & 0.546 & 0.9688 \\
13 & 1.472 & 0.8314 \\
14 & 0.463 & 0.9770 \\
15 & 0.921 & 0.9215 \\
\hline
\end{tabular}

\section{C) Stationarity Test}

Results of The stationarity test are shown in Figure 1: 
Inverse Roots of AR Characteristic Polynomial

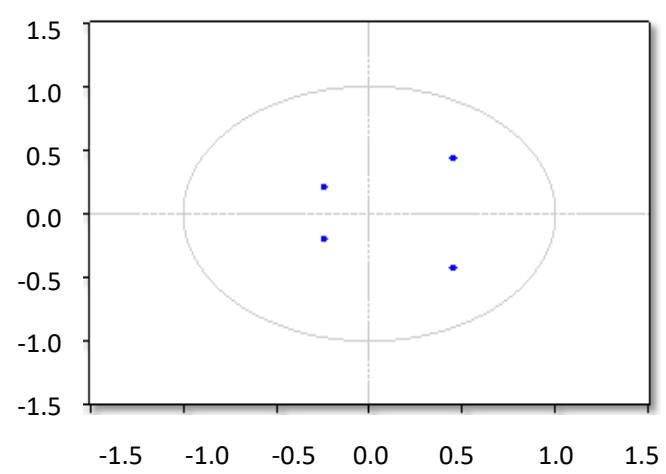

Figure 1. Stationarity test of VAR model

\begin{tabular}{cc}
\hline Endogenous variables: DLNHEPR GDPG & Exogenous variable: C \\
\hline Root & Modulus \\
\hline $0.455530-0.433709 \mathrm{i}$ & 0.6289 \\
$0.45530+0.433709 \mathrm{i}$ & 0.6289 \\
$-0.237936-0.204137 \mathrm{i}$ & 0.3135 \\
$-0.237936+0.204137 \mathrm{i}$ & 0.3135 \\
\hline
\end{tabular}

No root lies outside the unit circle

VAR satisfies the stability condition

Figure 1 shows that all the inverse roots of the many boundaries associated with the VAR are less than one, which proves the stability of the estimated model.

\subsection{Estimation of Response to Impulse Functions}

The impulse response functions of the model are displayed in the following figure:

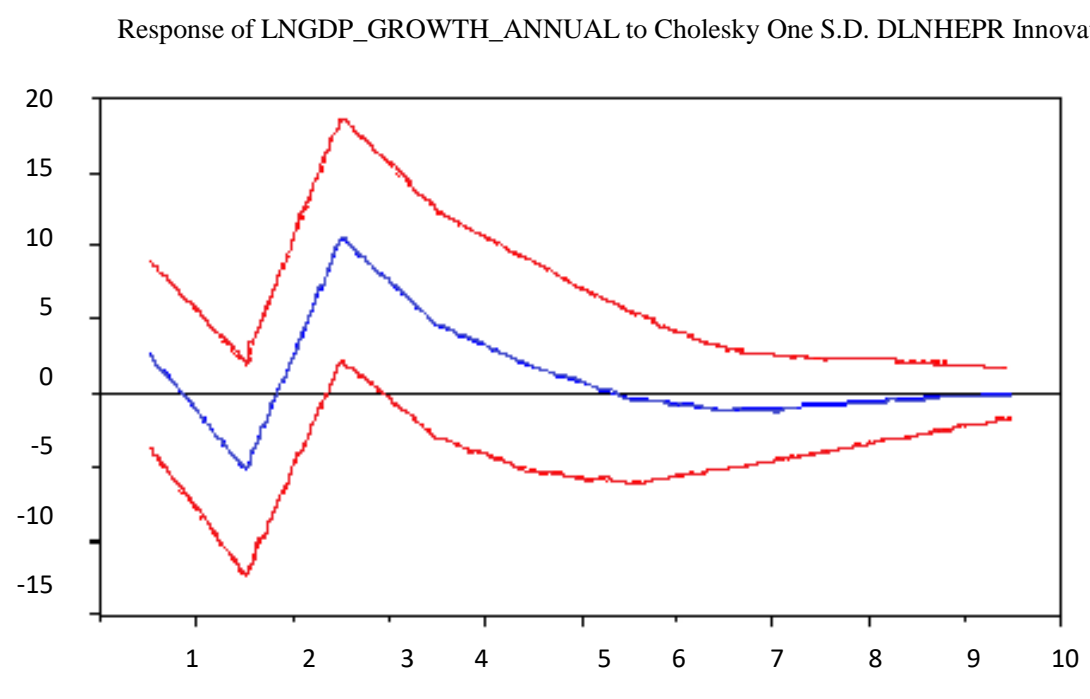

\begin{tabular}{rl}
\hline Period & \\
\hline 1 & 0.026563 \\
2 & $(0.03785)$ \\
& -0.052264 \\
& $(0.03954)$ \\
3 & 0.104503 \\
& $(0.05337)$ \\
4 & 0.046010 \\
& $(0.05609)$ \\
5 & 0.017843 \\
& $(0.05985)$ \\
6 & -0.003296 \\
& $(0.06178)$ \\
7 & -0.011116 \\
& $(0.05923)$ \\
8 & -0.008189 \\
& $(0.05901)$ \\
9 & -0.003261 \\
& $(0.06073)$ \\
10 & 0.000300 \\
& $(0.06732)$ \\
\hline
\end{tabular}

Figure 2. The VAR impulse response functions

The impulse response function, shown in Figure 2, shows that there is a negative response of GDP rates to one unit random shock of government expenditure on health during the first two years. After the second period, Government expenditure on health starts affecting positively GDP rate and continues until the fifth year. It is important to note that the response is significant during the third period, after which the GDP starts to decline until the tenth period. 


\subsection{Analysis of Variance of the Model}

Table 8 shows the variance decomposition analysis for some periods. Where it shows the source of changes that happen to the gross domestic product (GDP) when a random shock of government spending on health occurs in the 10 -year forecast horizon.

Table 8. Variance decomposition analysis

\begin{tabular}{lccc}
\hline Period & S.E & DLNHEPR & LNGDPG \\
\hline 1 & 0.014753 & 4.0264 & 95.9735 \\
2 & 0.015129 & 16.1809 & 83.8190 \\
3 & 0.015350 & 43.3171 & 56.6828 \\
4 & 0.015542 & 46.7185 & 53.2815 \\
5 & 0.015637 & 47.0496 & 52.9503 \\
6 & 0.015650 & 46.9634 & 53.0365 \\
7 & 0.015654 & 47.1215 & 52.8784 \\
8 & 0.015658 & 47.2199 & 52.7800 \\
9 & 0.015661 & 47.2328 & 52.7671 \\
10 & 0.015661 & 47.2304 & 52.7695 \\
\hline
\end{tabular}

Results reveal that changes in the gross domestic product (GDP) in the first year are related to changes in government spending on health by $4 \%$. This value increases over the years to reach $43 \%$ in the third year and continues to increase to touch $43 \%$ in the tenth. It is also noted that the auto impact of GDP represents $96 \%$ of the change in GDP during the first year, and this effect gradually decreases to 53\% in the tenth year.

\section{Conclusion}

The current study reveals that health spending has a positive effect on the Algerian economic growth. This result is consistent with that of Atilgan, Kilic, and Ertugrul (2016) in Turkey; Piabuo and Tieguhong (2017) in the EMCCA countries; Sunday (2017) in Nigeria and, Gangal and Gupta (2013) in India.

The study is partly in line with the study of Maitra and Mukhopadhyay (2012) which included 12 countries in Asia and the Pacific. Where findings revealed a negative impact of health spending on economic growth in three countries (Kiribati, Maldives and Vanuatu). The study is also partly in line with that of Mohapatra and Mishra (2011) in India; Bakare and Sanmi (2011) in Nigeria, and that of Akram and HaqPadda (2008) in Pakistan.

In terms of time scale, results of the present study are consistent with those of Atilgan, Kilic, and Ertugrul (2016) in Turkey in addition to those of Mohapatra and Mishra (2011) in India, which proved that the effect of health expenditure on GDP was on the short and long-term at the level of selected Indian states.

This study also agrees with all the reviewed studies about the direction of the causality relationship (the effect of health expenditure on economic growth), except the studies of Yazdi and Khanalizadeh (2017) and Sunday (2017).

The study points out the followings:

- $\quad$ The variables of the study were not stable, but stabilized when taking the first class differences.

- Granger's causality reveals that there is a positive correlation between the rate of health expenditure and the rate of economic growth; while the absence of correlation on the opposite direction.

- There is no causal relationship between health expenditure and growth rate in the long-term.

- There is a positive impact of the of health expenditure ratio lagged by one period on the growth rate of GDP.

Based on the present study's findings, it is recommended to:

- $\quad$ Raise the health spending rates since they have positive impact on economic growth, especially in light of the demographic and epidemiological transformation in Algeria, provided that the return on investment is achieved.

- $\quad$ Build a health structure in which both to the public health sector and the private health sector contribute; without compromising the conditions of equitable distribution of health service and its quality, for the sake of a health development and a sustainable economic growth in Algeria. 


\section{References}

Akram, N., \& HaqPadda, I. (2008). The long Term Impact of Health on Economic Growth in Pakistan. The Pakistan Development Review, 47(4), 487-500. https://doi.org/10.30541/v47i4IIpp.487-500

Ali, U. S., Khalaf, F. I., \& Al-Hiti, A. H. (2009). The relationship between spending on health, education and economic growth in the analytical study of both the economy of Jordan and Saudi Arabia for the period 1981-2006. Iraqi Journal for Economic Sciences, 7(20), 35-52.

Atilgan, E., Kilic, D., \& Ertugrul, H. M. (2016, June). The dynamic relationship between health expenditure and economic growth: is the health-leg growth hypothesis valid for Turkey? The European Journal of Health Economics, 18(5), 567-574. https://doi.org/10.1007/s10198-016-0810-5

Bakare, A. S., \& Sanmi, O. (2011). Health Care Expenditure and Economic Growth in Nigeria: An Emperical Study. Journal of Emerging Trends in Economics and Management Sciences, 2(2), 83-87.

Cornillou, G. (2012). Croissance et dépenses de santé. Les Tribunes de la santé, 3(36), 29-40. https://doi.org/10.3917/seve.036.0029

Gangal, V., \& Gupta, H. (2013). Public Expenditure and Economic Growth: A case Study of India. Global Journal of Management and Business Studies, 3(2), 191-196.

Gounash, A. H. (2004). Health and General Health Issued in the OIC Member Countries: The Relationship between Income and Health. Journal of Economic Cooperation among Islamic Countries, (25), 116-117.

Kaddouri, T. (2016). Contribution to Rationalizing Government Spending on Economic Development in Algeria Applied for the Study Period (1990-2014). Economic Vision, (11), 95-110. https://doi.org/10.12816/0036778

Kocoglu, Y., \& David, R. D. (2009). Santé et croissance de long terme dans les pays développés: une synthèse des résultats empiriques. Economie Publique, 24-25, 41-72. https://doi.org/10.4000/economiepublique.8478

Maitra, B., \& Mukhopadhyay, K. C. (2012, December). Public spending on education, health care and economic growth in selected countries of Asia and the pacific. Asia-Pacific Development Journal, 19(2), 19-48. https://doi.org/10.18356/e7c7bcb7-en

Michael, S., \& Maureen, L. (2009). Health and Growth: Commision on Growth and Development. Washington: The International Bank for Reconstruction and Development / The World Bank.

Mohapatra, S., \& Mishra, P. (2011, May). Composition of Public Expenditure on Health and Economic Growth: A cointegration Analysis and causality Testing. Journal of Public Finance, 9(2), 30-43.

Mukhtar, E. M. (2013). The Economics of Health Care Services in Developing Countries and their Impact on Development. American Arabic Academy of Science and Technology, 4(10), 121-138.

Piabuo, S. M., \& Tieguhong, J. C. (2017). Health expenditure and economic growth - A review of the literature and an analysis between the economic community for central African states(CEMAC) and selected African countries. Health Economic Review, 7(23). https://doi.org/10.1186/s13561-017-0159-1

Sunday, O. C. (2017). Public Expenditure on Health Care and Economic Growth in Nigeria: 1980-2015. Middle East Journal of Scientific Research, 25(5), 1057-1062.

Yazdi, S. K., \& Khanalizadeh, B. (2017). Air pollution, economic growth andd health care expenditure. $\begin{array}{llll}\text { Economic Research-Ekonomska } & \text { Istrazivanja, } & 30(1), & 1181-1190 .\end{array}$ https://doi.org/10.1080/1331677X.2017.1314823

\section{Copyrights}

Copyright for this article is retained by the author(s), with first publication rights granted to the journal.

This is an open-access article distributed under the terms and conditions of the Creative Commons Attribution license (http://creativecommons.org/licenses/by/4.0/). 